\title{
Laparoscopic approach for duodenal carcinoid
}

\author{
Petra Gunkova, Igor Gunka, Jan Dostalik, Lubomir Martinek, Miroslav Mazur \\ Department of Surgical Studies, Faculty of Medicine, University of Ostrava, Czech Republic
}

Videosurgery and Other Miniinvasive Techniques 2012; 7 (2): 140-143

DOI: 10.5114/wiitm.2011.25778

\begin{abstract}
Carcinoids are a heterogeneous group of neuroendocrine tumours. Duodenal localization is associated with relatively benign behaviour of the tumour, slow progression, low metastatic potential, and absence of endocrine activity. Type and extent of surgery depend on size and staging of the tumour. In this article, we present a case study of a 27-yearold female patient with well-differentiated carcinoid in the second part of the duodenum. The tumour of a size $5 \mathrm{~mm}$ $\times 3 \mathrm{~mm} \times 2 \mathrm{~mm}$ manifested with abdominal symptomatology and did not invade the muscularis propria. Scintigraphy did not demonstrate other pathological deposits of somatostatin receptors. The wedge resection of the duodenal wall was performed laparoscopically with perioperative endoscopic localization and marking of the tumour. Uneventful operation and postoperative course presents a contribution of miniinvasive surgery of specific duodenal lesions.
\end{abstract}

Key words: duodenal carcinoid, neuroendocrine tumour, laparoscopy, perioperative gastrofibroscopy.

\section{Introduction}

Carcinoids are neuroendocrine tumours that originate in enterochromaffin cells lining the gastrointestinal tract, retroperitoneum and large bronchi. Histologically, carcinoids are similar to classic carcinomas but they are of different biological behaviour and secretory activity. The term "carcinoid tumour (carcinoma-like)" was coined in 1907 by Siegfried Oberndorfer [1]. Duodenal carcinoid tumours according to the Williams and Sander classification [2] are categorized as tumours originating from the so-called embryonic foregut. Carcinoids located in the duodenum are relatively benign because they typically have slow growth and low metastatic potential, and lack any endocrine activity.

Possible therapeutic options include endoscopic duodenal carcinoid excision, transduodenal excision, wedge resection of the duodenum, segmental and distal duodenectomy, and duodenopancreatectomy. The type of surgery depends on tumour size and staging. Extensive locoregional resection is indicated especially for tumours larger than $2 \mathrm{~cm}$.

With the increased use of minimally invasive surgery, resection of the duodenum can be performed laparoscopically in combination with the use of intraoperative endoscopy [3]. A prerequisite for this type of operation is accurate preoperative localization of the lesion and establishment of exact tumour staging [4].

\section{Case report}

A 27-year-old patient was investigated for 18-month colicky abdominal pain in the epigastrium and right hypochondrium. Abdominal sonography examination showed multiple cholecystolithiasis and subsequent gastrofibroscopy examination revealed a small, hemispherical tumour of size $5 \mathrm{~mm} \times 3 \mathrm{~mm}$ $\times 2 \mathrm{~mm}$ in the second part of the duodenum opposite the ampulla of Vater. Histology showed a well-differentiated endocrine tumour. The duodenum was examined by endosonography, which confirmed car- 
cinoid in the second part of the duodenum. Tumour size by endosonography was $5-6 \mathrm{~mm}$, without evidence of invasion into the muscularis propria of the duodenal wall and without peripancreatic or celiac lymphadenopathy. Scintigraphy did not demonstrate pathological foci of somatostatin receptors and magnetic resonance imaging (MRI) enteroclysis did not demonstrate pathological organic changes of intestinal loops. Abdominal computed tomography (CT) was also negative. The levels of 5-hydroxyindoleacetic acid (5-HIAA) in 24-h urine collection was normal.

Laparoscopy was performed in the left lateral decubitus of the patient. Capnoperitoneum was created to a pressure of $12 \mathrm{mmHg}$. Distribution of trocars was as follows: $10-\mathrm{mm}$ port for the optics in the right mesogastrium, $10-\mathrm{mm}$ port infraumbilically, $12-\mathrm{mm}$ port in the midline $10 \mathrm{~cm}$ above the umbilicus and 5 -mm port in the right posterior axillary line. The first step in this procedure was mobilization of the hepatic flexure, followed by mobilization of the second and the third part of the duodenum. Using intraoperative endoscopy, a tumour of size $5 \mathrm{~mm}$ in diameter across the ampulla of Vater was localized (Figure 1). The exact location of the tumour on the duodenal wall was marked by a stitch. Using the linear endostapler technique, a wedge resection of the duodenal wall was performed (Figure 2). The operation was completed with concomitant cholecystectomy for cholecystolithiasis. The drain was placed in the subhepatic area (Figure 3). Amoxicillin/clavulanate was used prophylactically by intravenous administra-

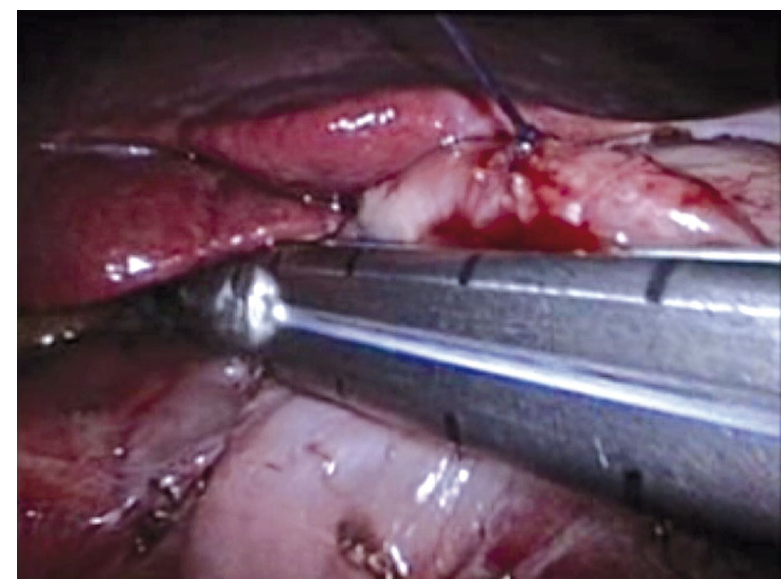

Figure 2. Wedge resection of the duodenal wall tion in a dose of $1.2 \mathrm{~g}$ every $8 \mathrm{~h}$ for 3 days. The operation lasted 190 min.

The postoperative course was uneventful. After surgery, the patient stayed in the intensive care unit for the first 3 days. On the $2^{\text {nd }}$ postoperative day, the nasogastric tube was removed, and on the $4^{\text {th }}$ postoperative day oral intake was begun. Bowel function returned on the $5^{\text {th }}$ postoperative day. The abdominal drain was removed on the $4^{\text {th }}$ postoperative day.

The patient was discharged to outpatient care on the $6^{\text {th }}$ postoperative day. The definitive histology of the tumour node of size $5 \mathrm{~mm} \times 5 \mathrm{~mm} \times 3 \mathrm{~mm}$ confirmed submucosally located well-differentiated carcinoid. A secondary finding was focal chronic active cholecystitis. The tumour was classified as T1NOMO, and the patient is in follow-up outpatient care at the gastroenterological clinic with regular laboratory

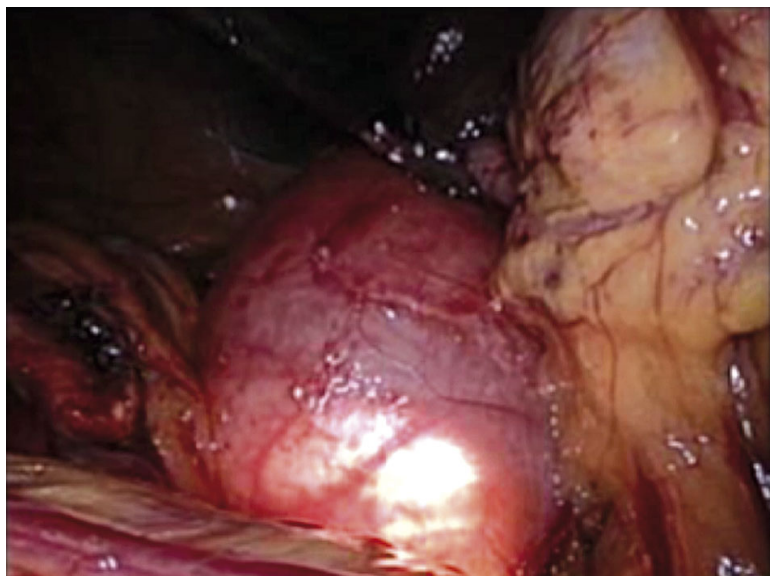

Figure 1. Intraoperative endoscopy

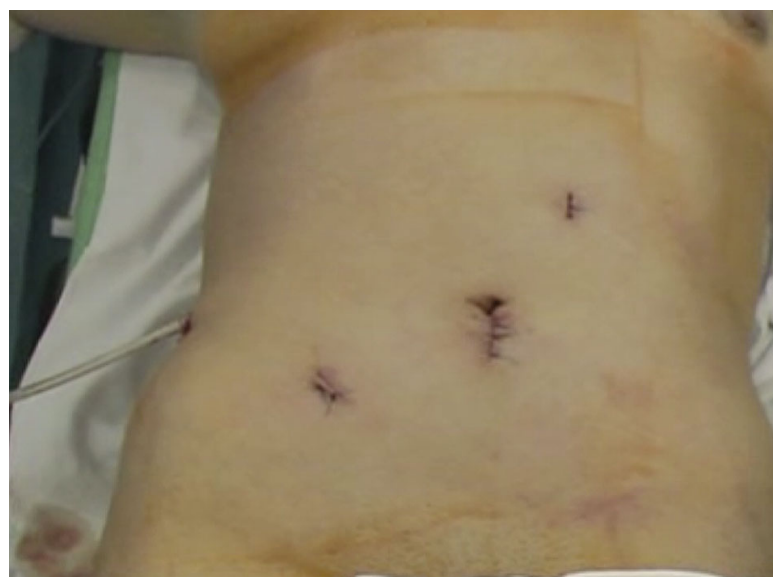

Figure 3. Abdomen after procedure 
screening of blood levels of 5-hydroxyindoleacetic acid and regular gastrofibroscopy and octreoscan examinations.

\section{Discussion}

Carcinoids represent a heterogeneous group of neuroendocrine tumours. Their incidence in the population is very low: 1 to 2.6 per 100000 population [5]. But given the slow growth of the tumour and its poor symptoms, the true incidence may be higher $[6,7]$. The national Czech statistics indicate 706 carcinoid tumours during a 5-year period, of which over $80 \%$ were located in the digestive system [8]. Some of these tumours are found accidentally, and the diagnosis is established only postoperatively by histological examination. Carcinoids are associated with increased incidence of other primary malignancies, especially colon adenocarcinomas, which are diagnosed in $10-20 \%$ of patients $[6,9]$. The most frequent localization in the gastrointestinal tract is the appendix, followed by the ileum and rectum [10].

Table I. Proposal for a TNM classification for endocrine tumours of the duodenum/ampulla/proximal jejunum

\begin{tabular}{|c|c|}
\hline$T-$ pri & mary tumour \\
\hline TX & Primary tumour cannot be assessed \\
\hline TO & No evidence of primary tumour \\
\hline $\mathrm{T} 1$ & $\begin{array}{l}\text { Tumour invades lamina propria or submucosa } \\
\text { and size } \leq 1 \mathrm{~cm}\end{array}$ \\
\hline $\mathrm{T} 2$ & Tumour invades muscularis propria or size $>1 \mathrm{~cm}$ \\
\hline T3 & Tumour invades pancreas or retroperitoneum \\
\hline T4 & $\begin{array}{l}\text { Tumour invades peritoneum or other organs for any } T \text {, } \\
\text { add for multiple tumours }\end{array}$ \\
\hline $\mathrm{N}-\mathrm{reg}$ & gional lymph nodes \\
\hline NX & Regional lymph nodes cannot be assessed \\
\hline NO & No regional lymph node metastases \\
\hline N1 & Regional lymph node metastases \\
\hline$M-$ dis & stant metastases \\
\hline MX & Distant metastasis cannot be assessed \\
\hline MO & No distant metastases \\
\hline M1 & Distant metastases \\
\hline
\end{tabular}

Duodenal carcinoid tumours constitute 3.4-11.9\% of duodenal neoplasms, and $0.7-1.8 \%$ of all primary small bowel neoplasms [11]. Most of them are located in the first or second part of the duodenum [6]. According to the Japanese study comparing duodenal carcinoids with carcinoids of other localization, the mean age of 55.9 years, a relatively small mean tumour size of $17.7 \mathrm{~mm}$, a low metastatic potential (27.4\%), and low incidence of the carcinoid syndrome (3.1\%) are typical for duodenal carcinoids [12].

Clinically, duodenal carcinoid tumour often shows signs of partial duodenal obstruction with symptoms of vomiting, abdominal pain or bleeding in the digestive tract. If it affects the ampulla of Vater, it can cause obstructive icterus or recurrent acute pancreatitis [13]. Symptoms of carcinoid syndrome with the secretion of vasoactive substances are exceptional.

In 2005, the European Neuroendocrine Tumor Society (ENETS) [14] defined a classification and treatment guidelines for neuroendocrine tumours (Tabes I-III).

Possible therapeutic options include endoscopic duodenal carcinoid excision, transduodenal excision, wedge resection of the duodenum, segmental and distal duodenectomy, and duodenopancreatectomy.

Table II. Proposal for disease staging for endocrine tumours of the duodenum/ampulla/proximal jejunum

\begin{tabular}{|c|c|c|c|}
\hline Stage I & $\mathrm{T} 1$ & NO & MO \\
\hline Stage Ila & $\mathrm{T} 2$ & NO & MO \\
\hline $11 \mathrm{~b}$ & T3 & NO & $\mathrm{MO}$ \\
\hline Stage IIla & T4 & NO & MO \\
\hline IIIb & any $\top^{\top}$ & N1 & MO \\
\hline Stage IV & any $\top^{\top}$ & any N & M1 \\
\hline
\end{tabular}

Table III. Grading proposal for foregut neuroendocrine tumours

\begin{tabular}{|lcc|}
\hline Grade & Mitotic count $(10 \mathrm{HPF})^{1}$ & Ki-67 index $(\%)^{2}$ \\
\hline G1 & $<2$ & $\leq 2$ \\
\hline G2 & $2-20$ & $3-20$ \\
\hline G3 & $>20$ & $>20$ \\
\hline
\end{tabular}

${ }^{1} 10 \mathrm{HPF}$ : high power field $=2 \mathrm{~mm}^{2}$, at least 40 fields (at 40x magnification) evaluated in areas of highest mitotic density, ${ }^{2}$ MIB1 antibody, \% of 2,000 tumour cells in areas of highest nuclear labelling 
The type of surgery depends on tumour size and staging. Extensive locoregional resection is indicated especially for tumours larger than $2 \mathrm{~cm}$ in diameter or for tumours of any size with lymph node metastases $[14,15]$. In contrast, duodenal carcinoids of sizes up to $1 \mathrm{~cm}$ in diameter, which do not reach into the muscularis propria, do not require such an extensive operation [14, 15]. Treatment of intermediate size tumours (i.e. $1-2 \mathrm{~cm}$ ) is a topic of controversy, with some recommending endoscopic removal in the absence of lymph node metastases, and others advocating surgical excision [15].

Endoscopic resection of mucous in the case of duodenal carcinoid tumours is limited by a higher risk of perforation, later duodenal stenosis, and by worse control of the procedure in the narrow lumen of the duodenum and thin duodenal wall.

An alternative solution is transduodenal excision of the tumour or wedge resection of the duodenum. Until 1997, when Van de Walle et al. [16] first described the successful resection of a duodenal tumour by the laparoscopic approach, these procedures were performed by laparotomy. Van de Walle performed this operation for a benign stromal tumour. Combined laparoscopic-endoscopic resection of the duodenum was described by Sato et al. [17] and Toyonaga et al. [3].

\section{Conclusions}

Based on the published literature and our experience, we can show the benefits of minimally invasive surgery in treating selected duodenal lesions. A prerequisite for this type of operation is accurate preoperative localization of the lesion and establishment of exact tumour staging.

\section{References}

1. Oberndorfer S. Karzinoide Tumoren Des Dünndarms. Frankf Ztschr F Path Wiesb 1907; 1: 426.

2. Williams ED, Sander M. The classification of carcinoid tumours, Lancet 1963; 238-9.

3. Toyonaga T, Nakamura K, Araki Y, et al. Laparoscopic treatment of duodenal carcinoid tumor. Surg Endosc 1998; 12: 1085-7.

4. Yoshikane $\mathrm{H}$, Tsukamoto Y, Niwa Y, et al. Carcinoid tumors of the gastrointestinal tract: evalution with endoscopic ultrasonography. Gastrointest Endosc 1993; 39: 375-83.

5. Hemminki K, Li X. Incidence trends and risk factors of carcinoid. Cancer 2001; 92: 2204-10.

6. Woodside KJ, Townsend CM, Evers BM. Current management of gastrointestinal carcinoid tumors. J Gastrointest Surg 2004; 8: 742-56.
7. Pazinka P, Soltes M, Medvecky V. Carcinoid- uncommon finding in patients with chronic pelvin pain? Slovensky chirurg 2003; 7 : 21-3.

8. Zamrazil V. Neuroendokrinní tumory. Interní Med 2007; 9: 514-9.

9. McCabe HL. Adenocarcinoma of the gastro- oesophageal junction with a synchronous carcinoid of the duodenum. Postgrad Med J 2001; 77: 255-6.

10. Modlin IM, Sandor A. An analysis of 8305 cases of carcinoid tumors. Cancer 1997; 79: 813-29.

11. Weiss NS, Yag CP. Incidence of histologic types of cancer of the small intestine. J Natl Cancer Inst 1987; 78: 653-6.

12. Soga J. Endocrinocarcinomas (carcinoids and their variants) of the duodenum. An evaluation of 927 cases. J Exp Clin Cancer Res 2003; 22: 349-63.

13. Lukáš M, Louthan O. Neuroendokrinní nádory trávicího traktu, Maxdorf, Praha 2006: 27.

14. Rindi G, Klöppel G, Alhman H, et al. TNM staging of foregut (neuro)endocrine tumors: a consensus proposal including a grading system. Wirchows Arch 2006; 449: 395-401.

15. Papageorgiou G, Lolis EV. Gastric and duodenal carcinoid tumours. Prevalence, tumour biology, diagnosis and surgical therapy. Hellenic J Surg 2011; 83: 4-11.

16. Van de Walle P, Dillemans B, Van de Lanotte M, Proot L. The laparoscopic resection of a benign stromal tumour of the duodenum. Acta Chir Belg 1997; 97: 127-9.

17. Sato T, Fukunaga T, Ohyama S, et al. Endoscopic total layer resection with laparoscopic sentinel node disection and defect closure for duodenal carcinoid. Hepatogastroenterology 2005; 52: 678-9. 